International Journal of Multidisciplinary Research AND ANALysis

ISSN(print): 2643-9840, ISSN(online): 2643-9875

Volume 04 Issue 11 November 2021

DOI: 10.47191/ijmra/v4-i11-07, Impact Factor: 6.072

Page No.- $1540-1542$

\title{
Activation of Vocabulary of Preschool Children on the Basis of Associative Experimental Method
}

\author{
Gulobod Rakhmatova \\ Lecturer, Navoi State Pedagogical Institute, Navoi, Uzbekistan
}

ABSTRACT: The article describes how to activate the vocabulary of preschoolers based on the method of associative experience, and also provides some recommendations for increasing the vocabulary of children. Associative experimental methods are presented.

KEY WORDS: Association, experience, vocabulary, stimulus, communication.

\section{INTRODUCTION}

The richness of the vocabulary indicates that the child's speech is highly developed. Enriching vocabulary is a prerequisite for developing children's communication skills. Preschoolers need to have a vocabulary that allows them to communicate with peers and adults, read successfully in school, understand literature, television and radio broadcasts, and more.

\section{THE MAIN FINDINGS AND RESULTS}

Vocabulary enrichment, consolidation and activation play an important role in the overall structure of the dictionary. The peculiarity of dictionary work is that it is mainly related to all types of activities for preschool children. The child learns the world around him, forms and develops the exact names of objects and events, their properties and attributes, their interrelationships, knowledge and ideas.

When working on a dictionary, the educator has the task not only to expand and increase the vocabulary, but also to form a correct understanding of their meaning (meaning) and use it meaningfully. Understanding the meaning of words (especially plurals) leads to an increase in vocabulary due to understanding other meanings of a known word. It helps to understand the meaning of words correctly, to develop the correct use of words, to improve children's speech, and in the future to improve the culture of speech.

It seems that the most important condition for the development of speech culture in preschool children is to work on the word. Fluency in the word, comprehension of its meaning, correct use of the word are necessary for the child to master the grammatical structure of the language, to master the phonetic side of speech, to develop the ability to speak independently and consistently.

When talking about the assimilation of a word by preschool children, it should be noted that if the learning to use a word is related to its meaning and the child is able to establish associative connections, it will be faster and stronger. '

The associative method plays an important role in the organization of the lexical system, because it allows the child to get an objective idea of the existing semantic connections of words formed on the basis of experience. The use of the associative method reveals the peculiarities of the understanding of a polysemous word, the orientation of the child from the form of the word to the meaning, and develops his ability to use words correctly in semantic relations. Associative experience forms a mechanism for choosing words, because when choosing a word for a response, the child looks for the word in any semantic space, which allows him to think coherently. The associative experience (when children are given a stimulus word and they say their response) allows the educator to make a qualitative assessment of the child's vocabulary and shows how well he or she has developed the ability to search for the word. In addition, the associative experience demonstrates the child's ability to choose the most appropriate word for a particular context, as well as the ability to use the word in a variety of phrases, sentences, and coherent sentences. The combination of semantic and associative aspects to form a child's system of meanings, word selection, 


\section{Activation of Vocabulary of Preschool Children on the Basis of Associative Experimental Method}

search engine, and their connections not only improve the lexical side of the language, but also create favorable conditions for the speech development of preschool children.

For the first query (at the beginning of the school year) you can suggest 15 poly-semantic words (five each): horse needle, pen, bell, lightning, notebook; quality - old, light, heavy, sharp, hard; verb - to go, to stand, to strike, to swim, to pour.

Assignment 1 . The educator says to the child, "Come on, let's play a word game with you. I will tell you my word, and you will tell me your word. Tell me what comes to mind. Tutor: needle; Child: seamstress. This can be recorded on a dictaphone. Subsequent words are similarly associative.

Assignment 2. When all the words have been answered, the child returns to the first answer. "I said the word needle, why did you choose the word seamstress? Can You Explain? Explanations (interpretation of the meaning of words) are also recorded on a dictaphone - an important indicator of the development of children's speech.

Assignment 3. Create a story (tale) on the topic of needles. This task reveals that children understand different meanings of the word poly-semantic and have the ability to reflect this concept in the plot. It is advisable to record the story on a dictaphone (tape recorder) or in the form of a written speech.

The educator should speak slowly so that the child can clearly record the conversation on the dictaphone, to analyze which sentences the child uses for the story: simple or complex, grammatically correct and relevant, whether the story is presented in a logical sequence should pay attention to whether.

After completing the three tasks, the children's answers are analyzed. The associative experience first reveals how well the child understands the meaning of the words. If in the word needle the child gives different meanings of the word: stitch (thread, stitch, sharp), hedgehog (hedgehog, thorn), spruce (tree, green), etc., it indicates a high level of his speech development shows. The word spoken by the child may be partially or completely unrelated to the meaning of the stimulus. It also clarifies whether the child understands the different meanings of a polysemous word, pays attention to one of its meanings, or does not understand the meaning of the word at all.

All of the children's responses to Task 1 can be divided into the following types of reactions:

1) The meaning of the stimulus corresponds to the word:

- by similarity (needle - thread);

- by differences (heavy - light, hard - soft);

- depending on (bell - at the door, lightning - rain);

- The principle of formation in the structure of the phrase: (went - went, call - rang);

2) stimuli are associated with insignificant signs in the word:

- by pronunciation similarity (needle - button; bell-puppet);

- according to the representation of the whole and the part (notebook - sheet);

3) Say words that are not related to the word stimulus:

- needle - book, swimming - table;

4) negative reactions (silence, "I do not know").

\section{CONCLUSION}

In general, the analysis of children's responses shows that preschool-aged children are well versed in the semantic side of the word, but not all children understand the meaning of polysemous words and that these meanings are used in different contexts. cannot apply. An analysis of the survey results shows that the understanding and conscious use of poly-semantic words depends on the general speech and mental development of preschool children, the strategy of learning the mother tongue, and the individual characteristics of the child.

\section{REFERENCES}

1) Lutfullayeva D., Davlatova R., Tadjibayev B. Associative Dictionary of the Uzbek Language. Publishing house "Navoi University". Tashkent 2019

2) Rakhmatova G. Methodology of formation of associations in the pre-school age magazine "Internauka" № 19 (148), Chast 2, 2020

3) Lutfullayeva D.E. Theory of associative linguistics. Tashkent: "Meriyus", 2017.-149b

4) Novikova A.M. Associative fields in the language and in the structure of the literary text: Avtoref.diss. ... Candidate of Philological Sciences - M., 1998.

5) Rakhmatova, G. (2021). ASSOCIATION FORMATION TECHNIQUE IN PRESCHOOL CHILDREN. CURRENT RESEARCH JOURNAL OF PEDAGOGICS (2767-3278), 2(06), 11-13. 


\section{Activation of Vocabulary of Preschool Children on the Basis of Associative Experimental Method}

6) Rakhmatova, G. O. (2020). SEMANTICS OF THE SYMBOLS CONNECTED WITH COLOR IN THE QUATRAINS OF" DIVANI LUGATI-T-TURK". Theoretical \& Applied Science, (2), 558-562.

7) Lutfullaeva, D., Davlatova, R., \& Tojiboev, B. (2019). Associative Dictionary of the Uzbek Language. Tashkent:“NAVOIY UNIVERSITETI.

8) Lutfullaeva, D. (2021). Linguistic Principles of Naming Trade Objects in Uzbek Language. Psychology and Education Journal, 58(1), 1027-1032. 